\title{
If at first you don't succeed: The importance of persistence in managing refractory air leaks
}

\author{
Mara B. Antonoff, MD
}

\author{
From the Department of Thoracic and Cardiovascular Surgery, UT MD Anderson Cancer Center, Houston, Tex. \\ Disclosures: Author has nothing to disclose with regard to commercial support. \\ Received for publication Oct 9, 2016; revisions received Oct 9, 2016; accepted for publication Oct 11, 2016; \\ available ahead of print Nov 1, 2016. \\ Address for reprints: Mara B. Antonoff, MD, Department of Thoracic and Cardiovascular Surgery, UT MD \\ Anderson Cancer Center, 1400 Pressler St, Unit 1489, Houston, TX 77030 (E-mail: mbantonoff@ \\ mdanderson.org). \\ J Thorac Cardiovasc Surg 2017;153:e19-20 \\ $0022-5223 / \$ 36.00$ \\ Copyright (c) 2016 by The American Association for Thoracic Surgery \\ http://dx.doi.org/10.1016/j.jtcvs.2016.10.015
}

In this case report, Dr Spratt and colleagues ${ }^{1}$ describe the use of endobronchial valves for prolonged air leak management in a lung transplant recipient. The patient's case was challenging, with a refractory air leak requiring numerous efforts over an extended period of time to achieve resolution. The authors noted several aspects of this case that rendered the air leak particularly troublesome: The patient's comorbidities included Ehlers-Danlos syndrome and alpha-1 anti-trypsin deficiency, along with concomitant immunosuppression with corticosteroids inherent to posttransplant management. Although this unusual combination of medical problems does not occur often, the issue of persistent air leaks is of great familiarity to the readership. Analyses from the Society of Thoracic Surgeons General Thoracic Surgery database have suggested that at least $8 \%$ of patients undergoing pulmonary resection for primary lung tumors experience prolonged air leak for more than 7 days. $^{2}$ Thus, although it is not likely that this case represents a clinical entity that will be frequently encountered by others, lessons learned from the experiences described in this article may be applicable to a large number of patients with prolonged air leaks of various cause.

Although Spratt and colleagues ${ }^{1}$ have highlighted their use of the endobronchial valve, it is not entirely clear that the valve was the sole intervention that led to resolution of the refractory leak. In fact, as with many difficult clinical scenarios, the surgical care team simultaneously used a number of interventions, any of which may have been independently responsible for the end result. Alternatively, the leak may have resolved consequent to the ideal combination of treatment strategies, or perhaps, patience along with tincture of time might have led to the same outcome. Ultimately, it is not truly known which of the numerous interventions led to the final resolution of the leak. However, what is clear from this patient's story is that there are a number of tools available to the surgeon managing postoperative prolonged air leak, and that, as previously

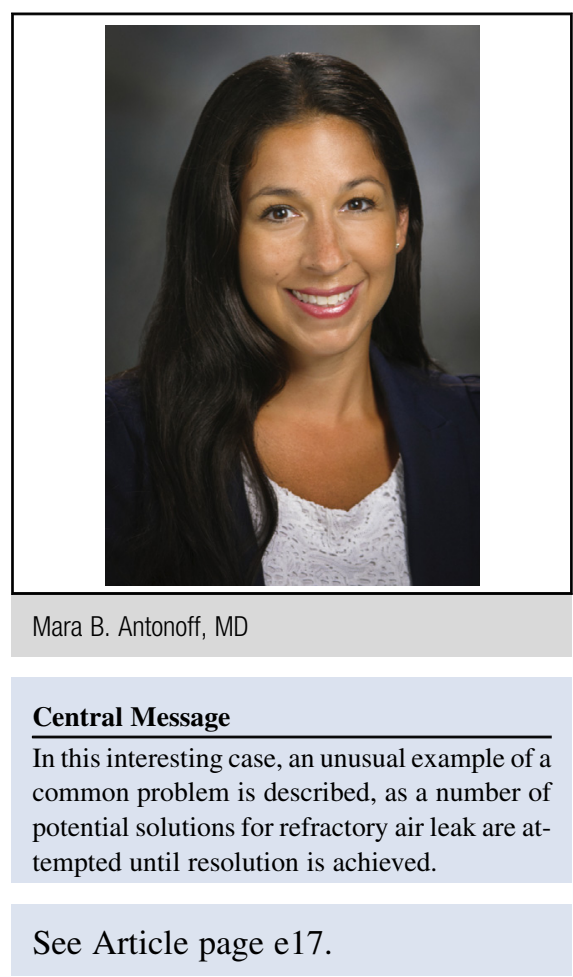

shown in other types of clinical scenarios, endobronchial valve therapy is a feasible and potentially helpful strategy within the armamentarium.

Perhaps the most important lesson learned from this article is the fact that when one strategy does not work, it may be worthwhile to try the same strategy again, to supplement with complementary efforts, and to continue tweaking until an acceptable response is achieved. The complexity of this case allowed Spratt and colleagues ${ }^{1}$ to present a full range of strategies to the readership: endobronchial valve placement, valve repositioning, chemical pleurodesis, blood patch, and therapeutic pneumoperitoneum. The honest description of the trial-anderror experience that ultimately led to the successful resolution of this patient's leak may be helpful to other clinicians strategizing management of prolonged leaks. It is important to note the strategy that is noticeably absent from this patient's care: return to the operating room. Although there may have been a number of issues that prevented operative management from being considered in this particular case (immunosuppression, hostile reoperative chest, need for urgent cholecystectomy), return to 
the operating room always should be present on the spectrum of interventions considered by the surgical team managing a prolonged air leak. Nonetheless, this interesting case serves as an excellent example of the potential utility of endobronchial valves in the management of such challenging patients.

\section{References}

1. Spratt JR, Podgaetz E, Loor G, Shumway SJ. Endobronchial valve therapy for a refractory air leak following lung transplantation in a patient with multiple connective tissue disorders. J Thorac Cardiovasc Surg. 2017;153:e17-8.

2. Boffa DJ, Allen MS, Grab JD, Gaissert HA, Harpole DH, Wright CD. Data from The Society of Thoracic Surgeons General Thoracic Surgery database: the surgical management of primary lung tumors. $J$ Thorac Cardiovasc Surg. 2008;135: 247-54. 